\title{
A imagem e a memória em Romance d'A pedra do reino
}

Tereza Pereira do Carmo

Doutoranda em Literatura Comparada / UFMG

\begin{abstract}
RESUMO
Este ensaio pretende analisar a questão da memória e da imagem em alguns folhetos do Romance d'A pedra do reino de Ariano Suassuna. Os percalços que levam Quaderna à prisão de onde traça seu memorial, em meio à narrativa vibrante e à apresentação de ilustrações produzidas pela técnica da xilogravura.
\end{abstract}

\section{PALAVRAS- CHAVE}

Suassuna, imagem, memória, xilogravura

O ser humano possui diferentes mecanismos de memória que estão associados aos cinco sentidos. Por esse motivo vamos nos limitar a memória advinda da preservação de imagens associadas à memória visual. Para tanto, ser-nos-á útil recorrer ao texto Imagens da memória, de César Guimarães. Nele o autor afirma que

(...) a memória é constituída por uma textura de imagens. Retratos, fotografias, descrições, cenas, composições pictóricas, enfim, signos ou conjuntos de signos que compõem uma imagem ou conjunto de imagens - esses são suportes nos quais a memória se inscreve, conformando múltiplas formas. ${ }^{1}$

A memória pessoal, nesse viés, acaba por se estruturar em signos que ultrapassam o limite do individual, ampliando-se e atingindo o coletivo; dessa forma, ela se torna memória coletiva que congrega imagens compactuadas no múltiplo. Aqui incorremos no perigo do senso comum. Uma memória coletiva poderia produzir o chamado conhecimento do senso comum? E, se assim fosse, as imagens produzidas poderiam ser falácias?

Recorro a Henri Bergson para um entendimento de memória. Segundo ele, existem duas memórias:

\footnotetext{
${ }^{1}$ GUIMARÃES. Imagens da memória (entre o legível e o visível), p. 30.
} 
Uma fixada no organismo, [que] não se é senão o conjunto de mecanismos inteligentemente montados que assegurem uma réplica conveniente às diversas interpelações possíveis. Ela faz com que nos adaptemos à situação presente, e que as ações sofridas por nós (...) antes hábito, do que memória, [sejam desempenhadas por] nossa experiência passada, mas [que] não evoca sua imagem.

A outra é a memória verdadeira. Coextensiva à consciência, ela retém e alinha uns após todos os nossos estados à medida que eles se produzem, dando a cada fato seu lugar, (....). ${ }^{2}$

Temos aqui uma memória ligada ao hábito, ao costume, que nos permite um comportamento social, respeitando as regras básicas da convivência em sociedade, desde as regras da etiqueta até o reconhecimento de um ente querido. E a outra que é, segundo o autor, a memória verdadeira e sobre a qual não temos controle. Tais memórias não se contrapõem nem são inimigas uma da outra, ao contrário, elas se completam. Onde uma é automática a outra é profunda, é lembrança, onde uma é presente a outra é evocativa. As duas estão em contínua interação.

A memória presente, também tratada como memória-lembrança, segundo Ecleia Bosi “se atualiza na imagem-lembrança (...) momento único, singular, não repetido”. ${ }^{3}$ Memória e imagem, de acordo com a mesma pesquisadora, estão vinculadas, inclusive na escrita.

Partindo dessas diretrizes teóricas e para tratar do tema "imagem e memória” na literatura de Ariano Suassuna, particularmente n'O romance d'A pedra do reino, ${ }^{4}$ farse-á necessário - para melhor entender o nosso ponto de vista sobre o objeto que desejamos observar - marcar pistas e traçar um caminho. Esse romance corresponde à primeira parte de uma trilogia, ainda inconclusa, idealizada por Suassuna. Apresentada em "folhetos, vinculada à tradição dos romanceiros medievais e segmentada conforme as técnicas do folhetim”, O Romance d'A pedra do reino mistura, em sua composição, vários gêneros literários; ${ }^{5}$ bem como em outros termos, a obra se compõe através da memória mesclada de formas literárias.

É sem dúvida uma obra de fôlego, que levou 13 anos para ser concluída, e que se confunde com fragmentos de memória da vida do autor, sobretudo na construção da personagem de Quaderna, na denúncia política e na crítica do homem sertanejo. Está

\footnotetext{
${ }^{2}$ BERGSON. Matéria e memória, p. 124.

${ }^{3}$ BOSI. Memória e sociedade, p. 48-49.

${ }^{4}$ Citaremos dessa forma a partir de agora.

${ }^{5}$ MICHELETTI. Na confluência das formas: o discurso polifônico de Quaderna/Suassuna, 1997 p. 14.
} 
dividida em cinco livros, constituídos por folhetos, nos quais são narradas as aventuras do já mencionado Quaderna, seus percalços que o levam à prisão de onde traça seu memorial, em meio à narrativa vibrante e emblemática e à apresentação de ilustrações produzidas pela técnica da xilogravura.

Poeta, filósofo, romancista e dramaturgo, Suassuna é referência na literatura brasileira e fundador do Movimento Armorial. ${ }^{6}$ Em entrevista aos Cadernos de Literatura Brasileira, do Instituto Moreira Salles, Suassuna postula, quando explicita a função da arte em sua vida, que “[o] que não tem salvação metafísica tem salvação estética”. ${ }^{7}$ Isso nos leva a pensar que, se a arte não precisa ter utilidade, ela pode ter a “função estética” de preservar ad aeternum a vida. Uma realização que mescla literatura, artes plásticas, filosofia e música, produzida com base na arte popular, por um autor de formação erudita e católica.

É na experimentação de misturas (da memória pessoal e da memória coletiva literária clássica, portuguesa e brasileira) que Ariano Suassuna cria um herói que se

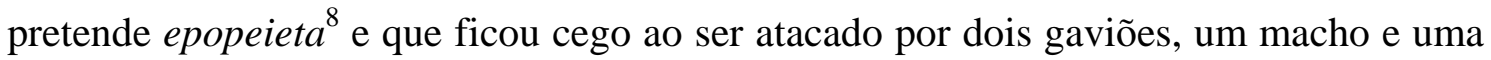
fêmea. É a partir desse cegamento inesperado que Quaderna, ou melhor, Pedro Dinis Quaderna, torna-se, à moda do cego fazedor de cantos épicos - e recorde-se que uma das etimologias do nome de Homero é cego ${ }^{9}$-, um contador de história ao relatar as aventuras e desventuras de sua vida e da condição humana. ${ }^{10}$

A cegueira, tema muito antigo, presente, no poeta cego que canta suas amarguras, é também motivo no mito de Édipo teatralizado por Sófocles e Sêneca. Ambos, em suas obras, narram a história a partir do misterioso flagelo, "a pavorosa peste" que se abateu sobre a cidade de Tebas. Em busca de uma explicação do inexplicável, os poetas figuram o atribulado rei à procura de um conhecimento oculto e vedado aos homens comuns. Édipo, o adotado do rei, pretende conhecer suas mais

${ }^{6}$ O Movimento Armorial tenta resgatar e conjugar a herança medieval portuguesa e romanceiro popular nordestino (literatura de cordel) Nele existe uma tendência para destacar uma estética que se compromete com a religiosidade e a transfiguração poética da realidade. (LEMOS. Ariano Suassuna, o palhaço-professor e sua Pedra do Reino, p.15)

${ }^{7}$ Em entrevista à publicação Cadernos de Literatura Brasileira, do Instituto Moreira Salles.

${ }^{8}$ Para o termo, propomos a seguinte etimologia: do grego, epos, palavra; poiéo, fazer e o sufixo marcador de diminutivo eta. O termo remete aos aedos gregos fabricantes de epoi, os cantadores do mediterrâneo.

${ }^{9}$ Cf. RENNÓ. O que é um autor? De Foucault e a questão homérica, p. 188.

${ }^{10}$ A obra de Suassuna foi representada no teatro com a direção de Antunes Filho (2006) e na televisão no do projeto Quadrante, dirigido por Luiz Fernando Carvalho (2007). 
remotas origens, pretende conhecer-se. Nesse processo, um dos pontos altos da tragédia consiste no entendimento de que, evitando o oráculo, cai-se no dito divino. Destarte, ao “ver” que possuiu a própria mãe depois de ter matado o pai, Édipo cega-se assombrosamente. Dir-se-ia que ele se cegou para não ver, mas, numa interpretação diferente, entendemos que Édipo é aquele que se cegou para melhor ver a sua patética situação.

Como afirma Sant’Anna, ${ }^{11}$ do Cego Aderaldo, repentista no sertão nordestino, à Grécia esses termos se complementam. "Furaram os óio do assum preto prá ele assim cantar melhor”, canta Luiz Gonzaga. ${ }^{12}$ Homero, como vimos, diz-se, era um bardo cego. Jorge Luis Borges, por ter problemas de visão desde a juventude e ter atingido a cegueira na vida adulta, concede ao binômio cegueira-visualidade um lugar de destaque em sua literatura. Brandão, ${ }^{13}$ em sua obra A última viagem de Borges, nos apresenta um Borges que afirma nunca se lamentar de sua cegueira por possuir uma visão interior. ${ }^{14} \mathrm{O}$ próprio Borges afirma em “A cegueira”:

O mundo do cego não é a noite que as pessoas supõem. Em todo caso, estou falando em meu nome e em nome do meu pai e minha avó, que morreram cegos; cegos, sorridentes e valorosos, como eu também espero morrer. Herdam-se muitas coisas (a cegueira, por exemplo), mas não se herda a coragem. Sei que foram valentes. ${ }^{15}$

E é comum aqui e ali encontrar o profeta, o sacerdote, o xamã ou o pajé, sempre e que, eternamente cegos, os que de dentro de sua cegueira, enxergam melhor de que toda a corte, toda a aldeia ou toda a tribo. É assim que Tirésias, o adivinho que aparece no mito de Édipo, sendo cego, é o que pode narrar e prever. É ele quem revela a Édipo o que, antes de cegar-se, Édipo ignorava.

A mitologia presente na construção da personagem Quaderna é um mestiço, ele vai além dos mitos clássicos greco-latinos. As profecias são exemplos disso. Elas surgem de duas formas, ora se referem a fatos que o narrador transmite ao leitor, ora são profecias enigmáticas. Para os fatos Quaderna recorre aos poetas da literatura brasileira, Álvares Azevedo, Gonçalves Dias, Augusto dos Anjos, Castro Alves, pois, os poetas

\footnotetext{
${ }^{11}$ SANT'ANNA. A cegueira e o saber, p. 11.

12 “Assum-preto”, criada em 1950 por Luiz Gonzaga e Humberto Teixeira.

${ }^{13}$ BRANDÃO. A última viagem de Borges - uma evocação.

${ }^{14}$ BRANDÃO. A última viagem de Borges - uma evocação, p. 30.

${ }^{15}$ BORGES. La ceguera, p. 276.
} 
são visionários: “'Os poetas são verdadeiros visionários’, isto é, gente que prediz o futuro e vê visagens e assombrações."16 Nas profecias enigmáticas Quaderna recorre a profetas e visagens de cantores sertanejos que possuem uma vertente apocalíptica.

Em sua ambição literária, o memorialista Quaderna se apropria dos textos de outros poetas. A apropriação de outros textos pela memória do narrador valoriza o texto e o escritor. Encontramos várias vozes no texto de Suassuna tanto da tradição quanto de diversos estilos.

A personagem Quaderna possui uma ambição literária que o leva a se comparar com grandes escritores, inclusive fisicamente. Ele se compara a Dostoiévski, Machado de Assis e principalmente aos escritores cegos, como Homero e Camões.

Se o fato de não ser cego significava alguma desvantagem em relação ao desgraçado do Grego Homero, a inferioridade estava, agora, sanada, graças às divindades de rapina da Morte Caetana. A contagem dos pontos até subira muito em meu favor, porque Homero era cego, mas não existira nem tinha sido completo. Eu, além de existir, ser completo, genial e régio, agora não deixara mais um flanco sequer aberto a meu adversário, pois até cego dos dois olhos conseguira me tornar! ${ }^{17}$

Aqui vemos a importância do Movimento Armorial, ou seja, a arte erudita brasileira fundamentada na cultura popular. Suassuna busca construir seu herói partindo das raízes populares da cultura brasileira que não são particulares e nem universais, mas possuem resquícios da cultura greco-latina, da cultura ibérica, medieval, entre outras. Encontramos um narrador que bebe desde a literatura de cordel passando pela literatura de vários povos e culturas.

Quaderna vai para a prisão, sua dignidade de descendente real, profeta, cronista, rapsodo, acadêmico e poeta está em jogo. A personagem se isola, não para fugir. Ao se isolar Quaderna vive uma série de aventuras na tentativa de ter outra vez sua identidade.

Qual identidade? Híbrida, pois a cultura erudita e a cultura popular estão presentes na mesma personagem. Não há hierarquia entre elas, convivem juntas no mesmo sujeito social.

Há na narrativa de Quaderna uma polifonia estratégica. Assim como a cegueira, a memória é intermitente. Vários discursos saem do baú da memória. Vários gêneros

\footnotetext{
${ }^{16}$ SUASSUNA. Romance d'A pedra do reino e o príncipe do sangue do vai-e-volta, p. 7.

${ }^{17}$ SUASSUNA. Romance d'A pedra do reino e o príncipe do sangue do vai-e-volta, p. 508.
} 
narrativos são utilizados pelo narrador, destacando o memorial. É assim que o narrador se apresenta:

Ora, eu, Dom Pedro Dinis Ferreira-Quaderna, sou o mesmo Dom Pedro IV, cognominado "O Decifrador”, Rei do Quinto Império e do Quinto Naipe, Profeta da Igreja Católico-Sertaneja e pretendente ao trono do Império do Brasil. Por outro lado conta da minha certidão de nascimento ter nascido eu na Vila de Taperoá. É por isso, então, que pude começar dizendo que neste ano de 1938 estamos ainda no "no tempo do Rei” e anunciar que a nobre Vila sertaneja onde nasci é o palco da terrível "desaventura" que tenho a contar. ${ }^{18}$

Recorrendo à memória o narrador utiliza a primeira pessoa e detalha as descrições do cenário, do espaço e das personagens.

Suassuna recorre às festas populares, ao folclore nordestino utilizando a memória coletiva. Recorre também à memória histórica político-social do Brasil e ainda a história da literatura.

Apropriando da memória histórica, Suassuna tem como ponto de partida o movimento messiânico com a volta de Dom Sebastião junto ao episódio de Pedra Bonita ocorrido por volta de 1836. Recorre também aos acontecimentos da história do Brasil das décadas de 1930 e 1940, em que Luis Carlos Prestes e Plínio Salgado formavam duas facções ideologicamente diferentes. Suassuna deixa essa questão clara na narrativa de Quaderna acerca das opções feitas por Samuel e Clemente:

\begin{abstract}
A partir de 1930, com a vida política brasileira se dividindo cada vez mais, os dois começaram a se radicalizar. Luis Carlos Prestes já fundara o Partido Comunista do Brasil, e Plínio Salgado o partido extremado da Direita, a Ação Integralista Brasileira. (...) Não é preciso dizer que Samuel entrou imediatamente para a Ação Integralista Brasileira, (...) Quanto a Clemente aderira furiosamente à Aliança Nacional Libertadora, (...) acontece que a luta ideológica travada entre os dois estendera-se do campo puramente político até o literário, o histórico e até o religioso, se posso falar assim. ${ }^{19}$
\end{abstract}

A tarefa desse narrador que não vê é criar para os interlocutores uma imagem a partir das suas memórias. O escritor Italo Calvino, ${ }^{20}$ em seu trabalho sobre visibilidade, aponta para a relação entre palavra e imagem ao destacar a visibilidade como um valor a ser preservado na escritura. Para o escritor estamos perdendo a capacidade de pensar por imagens. Dessa forma são apresentados dois movimentos: o que parte da palavra para

\footnotetext{
${ }^{18}$ SUASSUNA. Romance d'A pedra do reino e o príncipe do sangue do vai-e-volta, p. 5.

${ }^{19}$ SUASSUNA. Romance d'A pedra do reino e o príncipe do sangue do vai-e-volta, p. 195.

${ }^{20}$ CALVINO. Visibilidade.
} 
chegar à imagem e outro que parte da imagem visiva para se chegar à expressão verbal. Tanto em um movimento quanto em outro, explora-se a capacidade de imaginação, que, segundo Calvino, constitui uma competência humana a ser desenvolvida, numa possível pedagogia da imaginação. Dessa forma Quaderna abusa da palavra.

Não contentando com isso, temos ainda, para melhor ilustrar, várias gravuras acompanhadas de um texto explicativo ao longo da obra. São em torno de 26 ilustrações, à semelhança das xilogravuras que foram feitas, segundo o narrador, pelo seu irmão bastardo Taparica Pajeú-Quaderna. ${ }^{21}$

As gravuras apresentadas dão à obra uma característica cordelista, por serem semelhantes à moda de ilustração sertaneja. A xilogravura é a arte de gravar em madeira, teve sua origem provavelmente na China, sendo conhecida desde o século VI. No Ocidente, ela já se afirmou durante a Idade Média, através de iluminuras e confecções de baralhos. Até então, a xilogravura era apenas uma técnica de reprodução de cópias. Só mais tarde é que ela começa a ser valorizada como manifestação artística.

As gravuras, segundo Quaderna, devem ser anexadas aos autos da apelação do processo que ele está passando. ${ }^{22}$ Suassuna descreve fielmente a imagem e depois a expõe. Seria desnecessária a exposição, já que descrição dá ao leitor uma apropriação da imagem via narrativa? Por certo que não. O que exatamente provocam as figuras? De início, como já foi mencionado, elas trazem para o texto o estilo visual do cordel. Em segundo lugar, ao quebrar o processo imaginativo, o autor faz, com a exposição, uma recuperação - no meio erudito - da memória popular e coletiva de sua região, de seu país; fá-lo e arquiva mantendo-a presente na obra. As gravuras funcionam como um entreatro. As bandeiras passam, o leitor se diverte. É também curioso que a utilização dessa espécie de heráldica fará d’O romance da pedra do Reino um armorial, isto é, um livro em que se registram os brasões e as bandeiras da nobreza sertaneja. De todas as gravuras, neste breve ensaio, focalizaremos apenas três.

A primeira gravura que aparece na página 10 faz referência à cavalgada do rapaz do cavalo branco que busca na memória coletiva a alusão ao fato histórico descrito no folheto do cantador Lino Pedra-verde:

Dividida em dois Campos

- um Direito e outro Esquerdo -

\footnotetext{
${ }^{21}$ SUASSUNA. Romance d'A pedra do reino e o príncipe do sangue do vai-e-volta, p. 9.

${ }^{22}$ SUASSUNA. Romance d'A pedra do reino e o príncipe do sangue do vai-e-volta, p. 9.
} 
Tinha três Onças vermelhas

Em campo de Ouro - o Direito -

E Contra- arminhos de Prata

Semeando o Campo negro. ${ }^{23}$

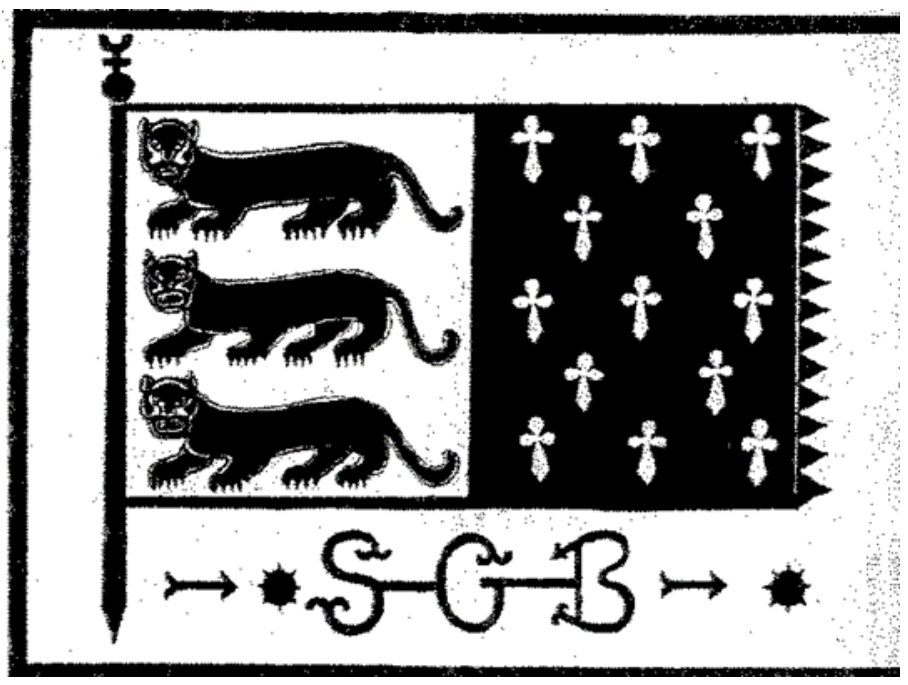

Figura 1 - Bandeira das onças, que vinha na cavalgada do rapaz do cavalo branco.

Fonte: SUASSUNA. Romance d'A pedra do reino e o príncipe do sangue do vai-evolta, p. 10.

Para Suassuna, a onça é um animal heráldico mais peculiar da fauna brasileira. As onças representadas na bandeira eram as onças que acompanhavam o rapaz do cavalo branco, que, de acordo com a descrição feita por Quaderna, eram três: uma Onça-Pintada, uma Onça-Parda, conhecida no Sertão como Suçuarana e uma OnçaNegra, que é uma onça mestiça de negra e pintada. No entanto na bandeira, as três onças eram vermelhas e estavam em campo de ouro e no campo negro estavam os contraarminhos de prata.

O romance continua, a bandeira passa, mas fica guardada no armorial. À altura da página 112 o irmão de Quaderna faz uma segunda gravura que representa todo o universo do romance de Suassuna. No folheto XXII o narrador conta que seu irmão se inspirou no desenho do padre e faz uma nova figura:

Na parte de cima colocaria as duas torres de pedra, bem mais iguais e separadas, para ficar tudo mais claro. Entre as duas colocaria o Sol, signo astrológico macho (...) Na metade inferior, a cara do nosso bisavô, o Rei, vista bem de perto com a Coroa de Prata armada sobre o chapéu de couro, o Cetro na mão direita e o Báculo profético na esquerda, os ombros cobertos por um Manto, enfeitado com as cruzes do Cordão Azul dos Cristãos e com os crescentes do Cordão

\footnotetext{
${ }^{23}$ SUASSUNA. Romance d'A pedra do reino e o príncipe do sangue do vai-e-volta, p. 9.
} 
Encarnado dos Mouros. Nos quatro cantos da figura, colocaria os signos masculinos, guerreiros e populares do baralho. (...) Finalmente, ladeando a figura do Rei, os signos astrológicos de Marte e Escorpião, insígnias zodiacais daquele glorioso e terrível Quaderna. ${ }^{24}$

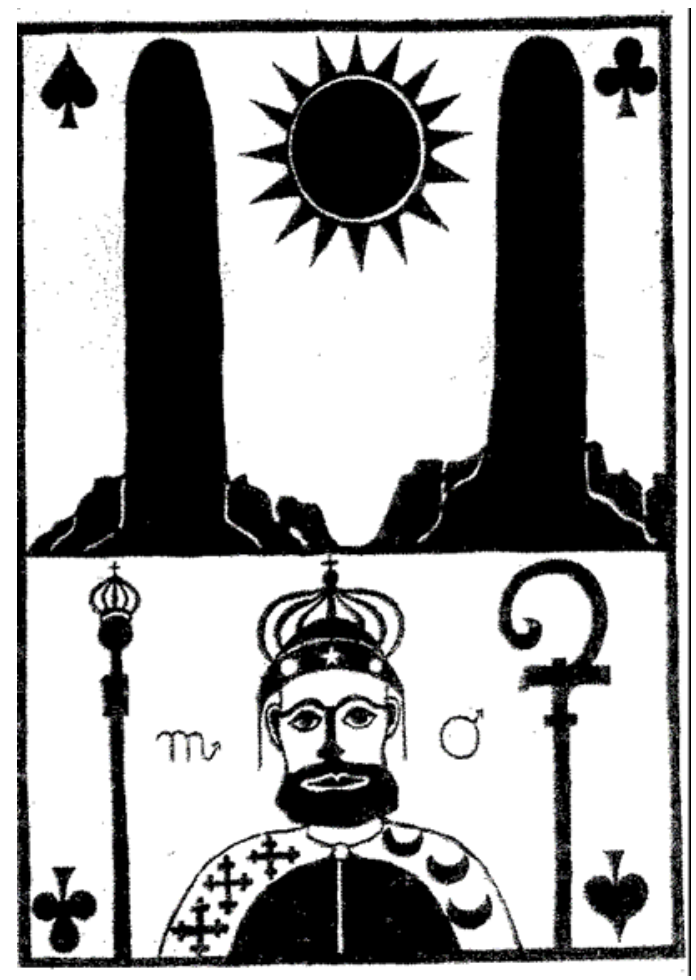

Figura 2 - Segunda gravura feita por Taparica sobre as pedras do reino e com meu bisavô Aproximado, tudo a partir do desenho do padre. Vê-se, perfeitamente, com absoluto rigor histórico, a coroa de prata dos Quadernas, montada sobre um chapéu de couro.

Fonte: SUASSUNA. Romance d'A pedra do reino e o príncipe do sangue do vai-evolta, p. 112.

Nota-se que as torres de pedras da imagem sobressaem como dois marcos fálicos, entre elas o sol, ao centro como símbolo astrológico da masculinidade, e a lua, símbolo do feminino que aparece na parte inferior. Assim, a Heráldica de Suassuna permite recuperar a estética regional, miscigenando o popular com o erudito e servindo de base às diversas manifestações do imaginário nordestino.

Nesses dois exemplos citados, podemos perceber que Suassuna utiliza o mesmo processo da sua narrativa, aproxima de outras narrativas pela técnica, pelo estilo, mas não utiliza o mesmo tema. As imagens revelam uma relação direta com o Movimento Armorial, que no ambiente de uma obra erudita apresenta a temática e a estética popular. No entanto, o escritor não se limita ao modelo de xilogravura da literatura de

\footnotetext{
${ }^{24}$ SUASSUNA. Romance d'A pedra do reino e o príncipe do sangue do vai-e-volta, p. 109.
} 
Cordel, o tributo ao cordel está na apropriação textual. O autor extrapola a temática do cordel, (príncipes, princesas, monstros) em suas imagens e expõe brasões, insígnias e escudos como os escudos de Clemente e de Samuel e também o escudo de Quaderna descrito abaixo:

É por isso que o Brasão dos Quadernas é uma variante do escudo dos Lacerdas, porque a cada mudança de nome, havia trocas de brasão. Por exemplo: desapareceu o castelo, um leão de púrpura virou veado negro, surgiu o timbre do cavalo castanho etc. As flores-de-lis porém permaneceram. Mas, o símbolo heráldico mais característico, mesmo, dos Quadernas é a quaderna de crescentes vermelhos e o grande veado negro inscrito nele. ${ }^{25}$

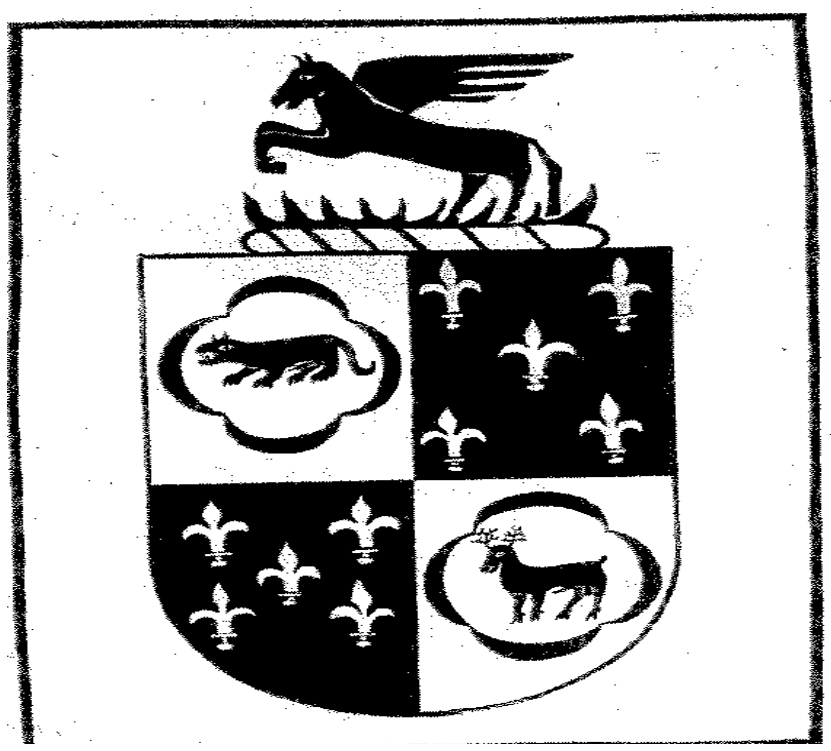

Figura 3 - Escudo de Armas de Dom Pedro Dinis Quaderna $12^{\circ}$ Conde da Pedra do Reino e $7^{\circ}$ rei do Quinto Império e do quinto naipe do sete estrelo do escorpião.

Fonte: SUASSUNA. Romance d'A pedra do reino e o príncipe do sangue do vai-e-volta, p. 660.

A descrição, incorporada ao texto literário, registra metamorfoses, novas composições pictóricas, "signos ou conjuntos de signos que compõem uma imagem ou conjunto de imagens", "suportes nos quais a memória sertaneja se inscreve, conformando as suas múltiplas formas.

Você deve estar se perguntando, caro leitor, o que há entre édipos, tiresias, cegos e profetas e as bandeiras. O próprio texto de Suassuna é recoberto de insígnias, que dá às imagens presentes nas bandeiras um tom épico. As ilustrações seguem as descrições

\footnotetext{
${ }^{25}$ SUASSUNA. Romance d'A pedra do reino e o príncipe do sangue do vai-e-volta, p. 559.
} 
de Quaderna, mas também os princípios da xilogravura nordestina. Certamente não resolveria a minha tese aqui nestas poucas páginas, mas adianto-lhes apenas que Quaderna nunca deixará de descrever as suas bandeiras e brasões para aqueles que não a podem ver com olhos que Deus lhes deu. De fato, a descrição serve para aqueles que veem com olhos que Deus tirou...

Afinal, repetimos: “os poetas são verdadeiros visionários’, isto é, gente que prediz o futuro e vê visagens e assombrações.” E as bandeiras e brasões são visagens de um futuro enobrecedor e, ao mesmo tempo, assombrações de um passado pesado de tradição.

Por fim, concluímos que, no nosso ponto de vista, pode-se considerar essa obra observando o conjunto imagem e texto, pois o texto e imagem - linguagens paralelas para os ouvidos e olhos - se suprem um ao outro, remediam a pobreza do ouvido solitário ou da escrita regular; imagem e texto se completam para constituir um armorial.

Se o texto memorialista aponta para fatos históricos e ficcionais que resgatam a memória coletiva, as imagens produzidas pelos textos possibilitam a confirmação da tese bergsoniana de memória hábito e memória verdadeira. Completa tal ideia as bases do Movimento Armorial, em que o erudito e o popular estão ligados. Nesse caso, as gravuras ficcionalmente feitas pelo irmão do protagonista Quaderna, mas que na realidade são obra do autor do texto, ${ }^{26}$ à semelhança das xilogravuras enquanto imagem que acompanha um texto, mostram que Suassuna não desejava apenas ilustrar o romance, mas registrar a memória da literatura de cordel e reforçar sua narrativa.

\begin{abstract}
This essay aims to examine matters concerning memory and image in some brochures of the novel Romance d'A pedra do reino by Ariano Suassuna. The mishaps that lead to the arrest of Quaderna where he sketched his memorial, through a vibrant narrative and the presentation of illustrations produced by the technique of woodcut.
\end{abstract}

\footnotetext{
${ }^{26}$ MOURA. Entre duas pedras: catolé (um estudo acerca das contribuições trazidas pelos textos históricos sobre Pedra Bonita e pelos folhetos de cordel nordestinos na composição de Pedra do Reino, de Ariano Suassuna), p. 49.
} 


\section{KEYWORDS}

Suassuna, image, memory, woodcut

\section{REFERÊNCIAS}

BORGES, Jorge Luis. La ceguera. In: Obras completas. Buenos Aires: EmecéEditores S.A, 2004. v. 3.

BRANDÃO, Inácio Loyola. A última viagem de Borges - uma evocação. São Paulo: Global. 2005.

BERGSON, Henri. Matéria e memória. Trad. Paulo Neves da Silva. São Paulo: Martins Fontes, 1990.

BOSI, Ecleia. Memória e sociedade. São Paulo: Cia das Letras, 1999.

CALVINO, Italo Visibilidade. In: Seis propostas para o próximo milênio. 2. ed. Trad. Ivo Barroso. São Paulo: Companhia das Letras, 1997. p. 95-114.

GUIMARÃES, Cesar. Imagens da memória (entre o legível e o visível). Belo Horizonte: Editora UFMG, 1997.

LEMOS, Anna Paula Soares. Ariano Suassuna, o palhaço-professor e sua Pedra do Reino. Disponível em: $<$ http://www.ciencialit.letras.ufrj.br/trabalhos/2007/annapaulalemos_arianosuassuna.p>. Acesso em: 12 dez. 2010.

MICHELETTI, G. Na confluência das formas: o discurso polifônico de Quaderna/Suassuna. São Paulo: Clíper Editora, 1997.

MICHELETTI, G. Na confluência das formas (estudo de uma narrativa compósita: A pedra do reino, de Ariano Suassuna). 1983. Dissertação (Mestrado) - Universidade de São Paulo.

MOURA, Débora Cavalcantes de. Entre duas pedras: catolé (um estudo acerca das contribuições trazidas pelos textos históricos sobre Pedra Bonita e pelos folhetos de cordel nordestinos na composição de Pedra do Reino, de Ariano Suassuna). (Dissertação de Mestrado). Campinas, 2002.

OLIVEIRA. João Vicente Ganzarolli de. Do essencial invisível: arte e beleza entre os cegos. Rio de Janeiro: FAPERJ/Ed. Renavan, 2002.

RENNO, Teodoro. O que é um autor? De Foucault e a questão homérica. Disponível em: <http://www.letras.ufmg.br/nuntius/data1/arquivos/006.12-Teodoro_Renno181200>. Acesso em: 5 dez. 2010.

SANT'ANNA, Affonso Romano de. A cegueira e o saber. Rio de Janeiro: Rocco, 2006. SUASSUNA, Ariano. Manifesto do Movimento Armorial. Recife: UFPE, 1976.

SUASSUNA, A. Romance d'A pedra do reino e o príncipe do sangue do vai-e-volta. Rio de Janeiro: José Olympio Editora, 1972. 